Christophe Milési

Félicie Ferragu

Samir Jaber

Aline Rideau

Clémentine Combes

Stefan Matecki

Jacques Bourlet

Jean-Charles Picaud

Gilles Cambonie

\title{
Continuous positive airway pressure ventilation with helmet in infants under 1 year
}

G. Cambonie (®)

Unité de Réanimation-Pédiatrique, CHU de Montpellier, Hôpital Arnaud de Villeneuve, 371 Avenue du Doyen G. Giraud, 34295 Montpellier Cedex 5, France e-mail: g-cambonie@chu-montpellier.fr Tel.: +33-467-336609

Fax: +33-467-336228

C. Milési - F. Ferragu · A. Rideau

C. Combes - J.-C. Picaud - G. Cambonie

Pediatric Intensive Care Unit,

CHU Montpellier, 34000 Montpellier,

France

\section{S. Jaber}

Intensive Care Unit and Transplantation

Department, CHU Montpellier,

34000 Montpellier, France

\section{S. Matecki}

Physiological Department, CHU

Montpellier, 34000 Montpellier, France

S. Jaber - S. Matecki

INSERM ERI 25, Université Montpellier I, 34000 Montpellier, France

J. Bourlet

CREFA, UFR Pharmacy,

Université Montpellier I, 34000

Montpellier, France

\begin{abstract}
Objective: To report the feasibility of helmet use in infants between 1 and 12 months old with acute respiratory failure. Design and setting: Observations were made before and $2 \mathrm{~h}$ after helmet CPAP of $6 \mathrm{~cm} \mathrm{H}_{2} \mathrm{O}$. Failure was defined as recourse to intratracheal ventilation. Patient stabilization or improvement was defined as a variation $<10 \%$ or a decrease $>10 \%$ in one of the following: respiratory rate, inspired oxygen fraction, or capillary partial pressure of $\mathrm{CO}_{2}$. Tolerance was assessed by the pain and discomfort score, the systematic search for pressure sores, and the measurement of helmet humidity and noise level. Results: Twenty-three infants with a median
\end{abstract}

age of 5 (2-8) months were included. Helmet CPAP failed in two (9\%) patients. Stability or improvement occurred in $16(70 \%)$ patients. The pain and discomfort score was stable or improved in $22(96 \%)$. Pressure sores were found in three $(13 \%)$ infants. Humidity was 98\% (98-99\%) and fell to $40 \%(39-43 \%)$ after the humidifier was stopped. The noise level in the helmet was 81 (7794) dB-SPL. Conclusions: The helmet was a satisfactory interface for CPAP delivery in young infants in more than two-thirds of the cases. Pressure sores can be prevented by placing a cushion in the helmet. Caregivers need to take into account the high humidity and noise levels of this interface.

Keywords Continuous positive airway pressure Helmet . Infant $\cdot$ Noninvasive ventilation

\section{Introduction}

In pediatric intensive care units (PICUs), noninvasive ventilation (NIV) failure ranges from 10 to $40 \%$ [1-3]. In infants under 1 year, the failure rate is even higher, mainly because of a misfit between the available interfaces and the infant face $[4,5]$. The helmet is a potential alternative because it avoids direct facial contact. It thus has been used in pediatrics since 2004 [6-8]. However, no study has yet focused on helmet use in the critical population of very young infants.

The main objective of this study was to report the feasibility of helmet use in infants ranging in age from 1 to 12 months. For this purpose, we evaluated the failure rate and the rate of patient stabilization following the placement of a helmet providing continuous positive 
airway pressure (CPAP) in young infants with acute respiratory distress. The secondary objectives were to report the side effects, the humidity, and the noise levels linked to the helmet interface.

\section{Materials and methods}

\section{Ethical considerations}

This prospective observational study was conducted in a PICU of a university hospital. Written authorization was obtained from the parents. The procedures reported are all in routine use in our PICU and did not require prior approval from the hospital ethics committee, according to French law.

\section{Patients}

All consecutive infants between 1 and 12 months requiring CPAP for acute respiratory distress (ARD) were eligible. Acute respiratory distress (ARD) was defined by the following criteria [9]: (1) dyspnea with a respiratory rate (RR) $>40$ breaths/min, accessory muscle use, and paradoxical abdominal respiration, (2) $\mathrm{PCO}_{2}>45 \mathrm{mmHg}$, and (3) $\mathrm{FiO}_{2}$ $>0.3$ to reach pulse oximetry $\left(\mathrm{SpO}_{2}\right)$ of $92-96 \%$.

Exclusion criteria were as follows: the need for immediate intubation, rapid disease progression such as severe hypercapnia and/or hypoxia, inability to clear secretions, impaired gag or cough reflex, and recent gastric surgery.

\section{Equipment}

We used the "4-Vent Neoped" helmet (Teleflex Medical, Le Faget, France). CPAP was generated with the Elisée 150 ventilator (Resmed, Savigny, France) equipped with a two-tube circuit and a heated humidifier (Fisher and Paykel 850, Villebon, France). We placed a plateau valve (straight connector 22M-22F, Intersurgical, Fontenay sous bois, France) on the helmet expiratory port to ensure a flow $>25 \mathrm{~L} / \mathrm{min}$ and to limit the risk of rebreathing. As the device is not equipped with an antisuffocation valve, this helmet CPAP system was connected to a ventilator that continuously monitored pressure and flow in the helmet circuitry. $\mathrm{FiO}_{2}$ was set to maintain $\mathrm{SpO}_{2}$ within the target range $(92-96 \%)$. The device was adjusted to deliver CPAP of $+6 \mathrm{~cm} \mathrm{H}_{2} \mathrm{O}$ via the helmet.

\section{Study protocol and evaluated parameters}

First, we assessed the stability of the patient. If $\mathrm{SpO}_{2}$ remained stable for $10 \mathrm{~min}$, the following parameters were evaluated $5 \mathrm{~min}$ before and $2 \mathrm{~h}$ after helmet placement: RR, $\mathrm{FiO}_{2}$, and $\mathrm{SpO}_{2}$, recorded with an Intellivue MP70 cardioscope (Philips Medical Systems, Heerlen, The Netherlands); capillary blood gases, with a Gem Premier 3000 analyzer (Instrumentation Laboratory, Orangeburg, SC, USA); and pain and discomfort, with the French EDIN scale, which ranges from 0 to 15 , with discomfort $>4$ [10].

We also evaluated humidity inside the helmet after $2 \mathrm{~h}$, with a Thermo-Hygro-Recorder (Sanwa Tsusho, Tokyo, Japan), and the noise level in dB-SPL, with a Type 2230 sonometer (Bruël and Kjaer, Nærum, Denmark). The inspiratory flow was measured with a spirometer in the first five patients (Resmed Saime, Savigny, France).

Last, the following information was documented by the PICU nursing staff: any local complications due to the helmet, including conjunctivitis, epistaxis, vomiting, and skin irritation according to the National Pressure Ulcer Advisory Panel (NPUAP) classification [11].

\section{Definitions}

Failure was defined by the need for intubation. The criteria for intubation included at least one of the following [12]: clinical signs of extreme fatigue, severe hypoxemia $\left(\mathrm{SpO}_{2}<92 \%\right.$ with $\left.\mathrm{FiO}_{2}>0.9\right)$, and severe respiratory acidosis $\left(\mathrm{PCO}_{2}>70 \mathrm{mmHg}\right.$ with $\left.\mathrm{pH}<7.25\right)$.

Deterioration was defined as an increase $>10 \%$, stability as a variation $<10 \%$, and improvement as a decrease $>10 \%$ in the respiratory parameters $\left(\mathrm{RR}, \mathrm{FiO}_{2}, \mathrm{PCO}_{2}\right)$ and EDIN score after helmet placement compared with before.

\section{Statistical analysis}

The distributions of continuous variables were tested with the Shapiro-Wilk method and not all were found to be normal. Thus, results are shown as medians and ranges and comparisons were made using nonparametric tests (Mann-Whitney and paired Wilcoxon). A $P$ value $<0.05$ was considered to indicate statistical significance.

SAS software was used for all statistical analyses (Cary, NC, USA).

\section{Results}

Twenty-three patients were enrolled during 2008. Seventeen patients $(74 \%)$ presented an acute exacerbation of chronic respiratory distress.

Failure occurred in two $(9 \%)$ infants, both intubated for severe laryngeal stridor. Five infants $(22 \%)$ did not stabilize following helmet CPAP but did not require 
intubation. Nasal CPAP (Infant Flow Ventilator, EME, UK) was applied in two infants who presented an increase in $\mathrm{PCO}_{2} . \mathrm{PCO}_{2}$ decreased in one but remained at the same level in the other. Three patients presented an increase in $\mathrm{RR}$, but helmet CPAP was continued because all other respiratory parameters were improved. RR decreased in two patients and remained stable in the third.

No significant difference in the baseline characteristics was observed between the $7(30 \%)$ infants for whom the helmet failed or did not stabilize respiratory distress and the $16(70 \%)$ infants who showed stabilized or even improved respiratory distress with the helmet (Table 1).

After $2 \mathrm{~h}$ of helmet CPAP, $\mathrm{FiO}_{2}$ significantly decreased, from $0.39(0.35-0.55)$ to $0.30(0.21-0.3)$, $P<0.05$, whereas $\mathrm{SpO}_{2}$ remained stable, from 96\% (95$97 \%$ ) to $94 \%(93-96 \%)$. RR, $\mathrm{PCO}_{2}, \mathrm{FiO}_{2}$, and EDIN score either stabilized or improved in 17/23 (74\%), 14/17 (82\%), 23/23 (100\%), and 22/23 (96\%) patients, respectively. Eighteen patients were maintained continuously in the device for $12 \mathrm{~h}$. $\mathrm{FiO}_{2}$ and EDIN improved from baseline to $12 \mathrm{~h}$, respectively, from $0.39(0.35-0.55)$ to 0.28 (0.21-0.3), $P<0.05$, and from $4(2-7)$ to $2(2-3)$, $P<0.05$ (Fig. 1).

The humidity inside the helmet was $98 \%$ (98-99\%), and the heated humidifier was therefore stopped. The humidity $1 \mathrm{~h}$ later was $40 \%(39-43 \%)$. The ambient humidity was $32 \%(31-36 \%)$. The noise level inside the helmet was 81 (77-94) dB-SPL and 61 (59-63) dB-SPL in the patient rooms during the same period. The inspiratory gas flow inside the helmet was 34 (30-37) L/min.

Helmet CPAP was continued for 48 (24-81) h. Pressure from the rigid frame of the helmet caused skin irritation within $24-48 \mathrm{~h}$ at the base of the skull in three of the first six patients, one stage 1 and two stage 2 of the NPUAP classification. From the seventh patient onward, a small cushion was placed in the helmet to prevent pressure sores, which was successful. No conjunctivitis, epistaxis, or vomiting occurred.

\section{Discussion}

Like Yanez et al. [4], we observed a rapid effect of helmet CPAP on respiratory parameters, particularly a reduction in $\mathrm{FiO}_{2}$. Failure or deterioration also appeared quickly, within $2 \mathrm{~h}$ [1]. Our failure rate was comparable to that of Codazzi et al. [7] in a series of infants less than 2 years old.

It is noteworthy that $\mathrm{PCO}_{2}$ improved in only 4 out of 17 patients, raising questions about the occurrence of $\mathrm{CO}_{2}$ rebreathing during helmet CPAP. Significant $\mathrm{CO}_{2}$ rebreathing has been observed in adults for fresh gas flows lower than $40 \mathrm{~L} / \mathrm{min}$. Although a $6 \mathrm{~L}$ hood washout probably requires lower flow than an adult hood of 12-18 L and infants under 1 year most likely produce less $\mathrm{CO}_{2}$ than adults, the risk of rebreathing must nevertheless be kept in mind during helmet use in infants [13, 14]. Moreover, high $\mathrm{PCO}_{2}$ would seem to be an indication for true NIV instead of CPAP. Yet NIV is difficult to achieve in young infants because of their poor mask tolerance [8], and true NIV is not possible with the helmet because of the low air flows at this age and poor helmet compliance, both of which combined prevent patient-ventilator
Table 1 Baseline characteristics of the population

\begin{tabular}{|c|c|c|c|}
\hline & $\begin{array}{l}\text { Failure or deterioration } \\
(n=7)\end{array}$ & $\begin{array}{l}\text { Stability or improvement } \\
(n=16)\end{array}$ & $P$ \\
\hline Age (months) & $4(3-6)$ & $5(3-8)$ & 0.32 \\
\hline Weight $(\mathrm{kg})$ & $5(4-5)$ & $5(4-7)$ & 0.47 \\
\hline PIM II (\%) & $3(3-3)$ & $4(0-4)$ & 0.5 \\
\hline Pathology, $n(\%)$ & & & 0.48 \\
\hline Bronchopulmonary dysplasia & $2(29)$ & $3(19)$ & \\
\hline Acute viral bronchiolitis & $1(14)$ & $4(25)$ & \\
\hline UAM/congenital stridor & $3(43)$ & $3(19)$ & \\
\hline Myopathy, SMA & $0(0)$ & $3(19)$ & \\
\hline Patent ductus arteriosus & $0(0)$ & $2(13)$ & \\
\hline Scimitar/HLH syndrome & $1(14)$ & $1(6)$ & \\
\hline Respiratory rate (breath/min) & $46(41-55)$ & $49(43-61)$ & 0.6 \\
\hline $\mathrm{FiO}_{2}$ & $0.36(0.32-0.48)$ & $0.4(0.33-0.5)$ & 0.52 \\
\hline $\mathrm{SpO}_{2}$ & $95(93-94)$ & $95(94-98)$ & 0.22 \\
\hline $\mathrm{PCO}_{2}(\mathrm{mmHg})$ & $55(46-71)$ & $54(49-64)$ & 0.75 \\
\hline $\mathrm{pH}$ & $7.35(7.34-7.37)$ & $7.45(7.43-7.47)$ & 0.66 \\
\hline EDIN & $5(3-6)$ & $4(2-7)$ & 0.86 \\
\hline
\end{tabular}

Values are median (Q25-Q75) or absolute frequencies (percentage), $P$ was determined with chisquared or Mann-Whitney test. $\mathrm{PCO}_{2}$ was measured on capillary blood gas sampling. For the distribution of pathologies, statistical testing was conducted on pathologies grouped as pulmonary, upper airway, neuromuscular, or cardiac

PIM II Pediatric Index of Mortality II, UAM upper airways malformation, SMA spinal muscular atrophy, $H L H$ hypoplastic left heart, EDIN Newborn pain and discomfort scale 

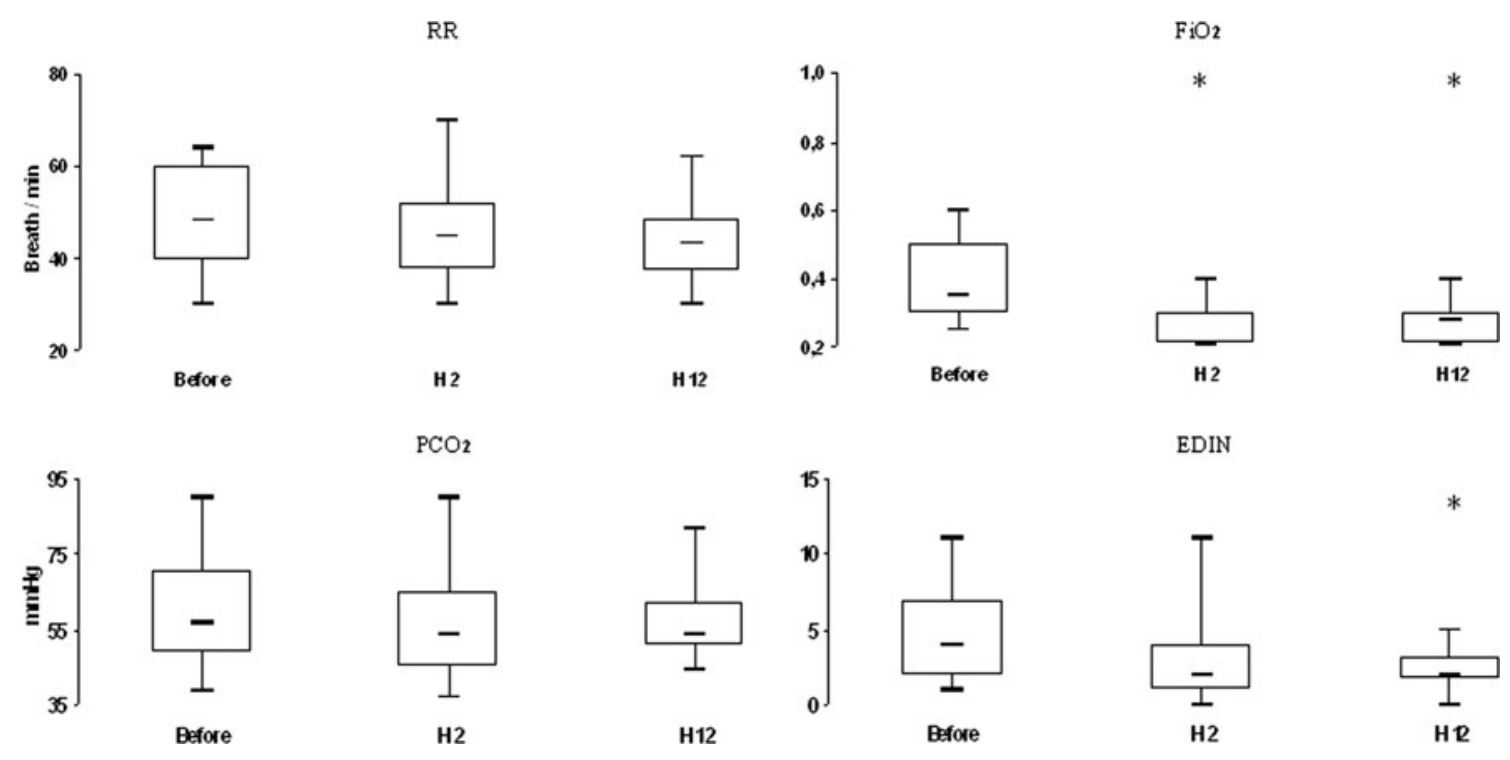

Fig. 1 Variations in respiratory parameters and EDIN score before, $2 \mathrm{~h}(H 2)$, and $12 \mathrm{~h}\left(\begin{array}{ll}H & 12\end{array}\right)$ after helmet CPAP. EDIN Newborn pain and discomfort scale, $\mathrm{FiO}_{2}$ fractional inspired oxygen (\%), $\mathrm{PCO}_{2}$

synchronization $[2,15]$. Thus, CPAP should be considered as a therapy of last resort in infant cases of hypercapnic respiratory distress, to be implemented exclusively in the PICU with extreme care $[5,8,16]$. Furthermore, during helmet CPAP in young infants, we recommend the continuous monitoring of inspiratory flow and patient blood gases using transcutaneous measurement. In neuromuscular diseases with chronic respiratory decompensation, NIV with pressure support should be established for daily assistance as soon as tolerated.

The noise level is a disadvantage of CPAP, whatever the interface. This level is proportional to the flow and can reach $90 \mathrm{~dB}-\mathrm{SPL}$ [17]. We measured the sound intensity in the helmet and not that perceived by the inner ear, which is attenuated by approximately $40 \mathrm{~dB}$ by the transcranial transmission of sound [18]. In any case, our measures exceeded the upper recommended limit of $45 \mathrm{~dB}-\mathrm{SPL}$ [19] and suggest prudence regarding the

partial pressure of carbon dioxide measured on capillary blood gas sampling ( $\mathrm{mmHg}), R R$ respiratory rate (breaths per minute). $* P<0.05$ by paired Wilcoxon test

prolonged use of helmet ventilation because of the potential long-term sensory consequences [20].

\section{Conclusion}

Our study was limited by the small number of subjects. Nevertheless, we found that the helmet interface was feasible and well tolerated in infants under 1 year needing CPAP. These results should be confirmed in a controlled study comparing the efficacy of several interfaces.

Acknowledgments We thank the nursing staff of the pediatric intensive care unit of Arnaud de Villeneuve University Hospital for their patience and cooperation, without which the study could not have been performed. We thank C. Stott-Carmeni for translating the manuscript and for editorial assistance. Last, we thank Mr. J. Noguez from the APARD association for his technical assistance.

\section{References}

1. Bernet V, Hug M, Frey B (2005)

Predictive factors for the success of noninvasive mask ventilation in infants and children with acute respiratory failure. Pediatr Crit Care Med 6:660 664

2. Essouri S, Chevret L, Durand P, Haas V, Fauroux B, Devictor D (2006) Noninvasive positive pressure ventilation: five years of experience in a pediatric intensive care unit. Pediatr Crit Care Med 7:329-334
3. Mayordomo-Colunga J, Medina A, Rey C, Díaz JJ, Concha A, Los Arcos M, Menéndez S (2009) Predictive factors of non invasive ventilation failure in critically ill children: a prospective epidemiological study. Intensive Care Med 35:527-536
4. Yañez LJ, Yunge M, Emilfork M, Lapadula M, Alcántara A, Fernández C, Lozano J, Contreras M, Conto L, Arevalo C, Gayan A, Hernández F, Pedraza M, Feddersen M, Bejares M, Morales M, Mallea F, Glasinovic M, Cavada G (2008) A prospective, randomized, controlled trial of noninvasive ventilation in pediatric acute respiratory failure. Pediatr Crit Care Med 9:484-489 
5. Cambonie G, Milési C, Jaber S, Amsallem F, Barbotte E, Picaud JC, Matecki S (2008) Nasal continuous positive airway pressure decreases respiratory muscles overload in young infants with severe acute viral bronchiolitis. Intensive Care Med 34:1865-1872

6. Piastra M, Antonelli M, Chiaretti A Polidori G, Polidori L, Conti G (2004) Treatment of acute respiratory failure by helmet-delivered non-invasive pressure support ventilation in children with acute leukemia: a pilot study. Intensive Care Med 30:472-476

7. Codazzi D, Nacoti M, Passoni M, Bonanomi E, Sperti LR, Fumagalli R (2006) Continuous positive airway pressure with modified helmet for treatment of hypoxemic acute respiratory failure in infants and a preschool population: a feasibility study. Pediatr Crit Care Med 7:455-460

8. Chidini G, Calderini E, Pelosi P (2010) Treatment of acute hypoxemic respiratory failure with continuous positive airway pressure delivered by a new pediatric helmet in comparison with a standard full face mask: a prospective pilot study. Pediatr Crit Care Med. doi:

10.1097/PPC.0b013e3181b8063b

9. American Respiratory Care Foundation (1997) Consensus conference: noninvasive positive pressure ventilation. Respir Care 42:364-369
10. Debillon T, Zupan V, Ravault N, Magny JF, Dehan M (2001) Development and initial validation of the EDIN scale, a new tool for assessing prolonged pain in preterm infants. Arch Dis Child Fetal Neonatal Ed 85:F36F41

11. Ankrom MA, Bennett RG, Sprigle $S$, Langemo D, Black JM, Berlowitz DR, Lyder $\mathrm{CH}$, National Pressure Ulcer Advisory Panel (2005) Pressure-related deep tissue injury under intact skin and the current pressure ulcer staging systems. Adv Skin Wound Care 18:3542

12. Liet JM, Millotte M, Tucci M et al (2005) Non invasive therapy with helium-oxygen for severe bronchiolitis. J Pediatr 147:812-817

13. Patroniti N, Foti G, Manfio A, Coppo A, Bellani G, Pesenti A (2003) Head helmet versus face mask for noninvasive continuous positive airway pressure: a physiological study. Intensive Care Med 29:1680-1687

14. Taccone P, Hess D, Caironi P, Bigatello LM (2004) Continuous positive airway pressure delivered with a "helmet": effects on carbon dioxide rebreathing. Crit Care Med 32:2090-2096

15. Moerer O, Beck J, Brander L, Costa R, Quintel M, Slutsky AS, Brunet F, Sinderby C (2008) Subject-ventilator synchrony during neural versus pneumatically triggered non-invasive helmet ventilation. Intensive Care Med 34:1615-1623
16. Antonelli M, Pennisi MA, Pelosi P, Gregoretti C, Squadrone V, Rocco M, Cecchini L, Chiumello D, Severgnini P, Proietti R, Navalesi P, Conti G (2004) Noninvasive positive pressure ventilation using a helmet in patients with acute exacerbation of chronic obstructive pulmonary disease: a feasibility study. Anesthesiology 100:16-24

17. Cavaliere F, Conti G, Costa R, Proietti R, Sciuto A, Masieri S (2004) Noise exposure during noninvasive ventilation with a helmet, a nasal mask, and a facial mask. Intensive Care Med 30:17551760

18. Surenthiran SS, Wilbraham K, May J, Chant T, Emmerson AJ, Newton VE (2003) Noise levels within the ear and post-nasal space in neonates in intensive care. Arch Dis Child Fetal Neonatal Ed 88:F315-F318

19. American Academy of Pediatrics. Committee on Environmental Health (1997) Noise: a hazard for the fetus and newborn. Pediatrics 100:724-727

20. Patuzzi R (1998) Exponential onset and recovery of temporary threshold shift after loud sound: evidence for longterm inactivation of mechano-electrical transduction channels. Hear Res 125:17-38 